\title{
A FORMAÇÃO CONTINUADA E O DESENVOLVIMENTO PROFISSIONAL DOS DOCENTES DA GRADUAÇÃO EM DESIGN EM UMA UNIVERSIDADE COMUNITÁRIA CATARINENSE
}

The continuing education and professional development of professors within the design course at a community university from Santa Catarina

Aguiar, Victor R. L.; Doutor - Mestrado Profissional em Design da Univille Universidade da Região de Joinville; cdht@uol.com.br

Everling, Marli; Doutora - Mestrado Profissional em Design da Univille - Universidade da Região de Joinville; meverling@gmail.com

Morgenstern, Elenir; Doutora - Mestrado Profissional em Design da Univille Universidade da Região de Joinville; elenir.m@gmail.com

Schulenburg, Larissa A.; Mestranda - Mestrado Profissional em Design da Univille Universidade da Região de Joinville; larissa.angeoleti@gmail.com

Resumo: O presente artigo visa apresentar opiniões dos docentes em relação a temática da formação continuada e o desenvolvimento profissional no curso de design em uma universidade comunitária catarinense. A pesquisa deu-se primeiramente com a abordagem histórica da instituição em questão para posteriormente discorrer sobre o Desenvolvimento Profissional Docente, Formação continuada e Desenvolvimento profissional. Com base neste referencial teórico, foi aplicada a pesquisa do tipo survey, a fim de obter opiniões dos docentes sobre a formação continuada oferecida na instituição. Com base nos dados coletados, verificou-se o descontentamento com as capacitações oferecidas, entretanto o professorado demonstrou bastante interesse em participar contribuindo com as temáticas de interesse a serem incluídas em futuras capacitações. Pôde ser visto também que os docentes são comprometidos com seu desenvolvimento profissional e procuram sempre se atualizar de forma autônoma. Ficou evidente também, a necessidade da instituição oportunizar conteúdos mais específicos por áreas de conhecimento, desta forma, contemplando demandas específicas de cada área.

Palavras-chave: docente, design, graduação, formação continuada, desenvolvimento.

Abstract: The purpose of this article is to present opinions of professors regarding the topic of continuing education and professional development within the design course in a community university from Santa Catarina. 
The research studied at first the historical approach of the institution to further discuss the Professional Development of Professors, Continuing Education and Professional Development. With this, a survey was conducted, in order to obtain opinions of professors regarding the continuing education and professional development offered at the institution in which this survey was applied. Based on the data collected, it was found the discontent of the trainings offered, however these professors showed great interest in participating in order to contribute with the subjects of interest and the ones included with most importance. It could also be seen that professors are committed to their professional development and seek to always update their knowledge autonomously. Finally it is suggested that the institution oportunize greater involvement of professors in their areas of knowledge and therefore contemplate specific demands of each área.

Key-words: Teaching, design, graduate, continuing education, development.

\section{INTRODUÇÃO}

Este artigo tem por objetivo apresentar a opinião que os docentes da Graduação em Design, em uma Universidade Comunitária Catarinense, têm acerca da formação continuada oferecida regularmente pela Instituição, manifestada por meio de uma pesquisa do tipo survey, realizada no final de 2012. Considerando que a formação continuada é um elemento fundamental para o desenvolvimento profissional docente, faz-se necessário verificar se as ações formativas institucionais estão alinhadas com as demandas docentes. Para tanto, será apresentado um breve histórico da Graduação em Design, desta Universidade, conceitos relacionados à temática (formação continuada e desenvolvimento profissional) e resultados da pesquisa.

\section{A GRADUAÇÃO EM DESIGN EM UMA UNIVERSIDADE COMUNITÁRIA CATARINENSE}

Para melhor compreensão do contexto da Universidade Comunitária Catarinense em questão, especificamente na Graduação em Design, apresentar-se-á um breve histórico acrescido de números demonstrativos da evolução, desde a implantação do curso, até o período atual.

De Acordo com o Projeto de Reestruturação do Curso de Bacharelado em Design da referida instituição, o curso foi criado em 1996 oferecendo as habilitações de Projeto de Produto e Programação Visual no turno matutino sob o regime anual com a duração de quatro anos e meio. Em 1999 o curso foi reestruturado e para refletir a natureza do projeto pedagógico a nomenclatura das duas habilitações passou a ser acompanhada da ênfase 'Gestão do Design', ainda em regime anual, mas com a duração de quatro anos.

Em 2002 foi criada a habilitação de Projeto de Produto com ênfase em 'Design de Mobiliário' no turno da noite sob o regime semestral. Este projeto pedagógico de curso foi o início da ação que posteriormente, em 2004, viabilizou a implantação das 
habilitações de Projeto de Produto e Programação Visual no turno da noite, também sob o regime semestral mas agora com a duração de quatro anos e meio.

Em 2006 foi criada a habilitação em Moda, oferecida no turno matutino, em regime anual e com a duração de quatro anos.

Em 2007 ocorreu a unificação do Projeto Pedagógico dos turnos diurno e noturno, previsto em regime anual e com a duração de quatro anos. Também em 2007 o projeto pedagógico do curso de Moda foi alterado, passando a ser oferecido nos turno noturno e matutino.

Em 2008 foi criada a habilitação de Animação Digital acompanhando o regime e a duração das demais habilitações sendo oferecido no turno da noite.

2010 foi o ano da criação da habilitação de Design de Interiores acompanhando a estrutura central, o regime e a duração das demais habilitações, também no turno da noite.

Salienta-se que a partir de 2007, tacitamente, a configuração dos projetos pedagógicos das habilitações convergiu para um núcleo central entre as disciplinas e demais elementos da proposta. Esta ação estava em sincronia com orientações do MEC (Ministério da Educação e Cultura) cuja orientação caminhava no sentido da extinção das habilitações. No âmbito do curso de Design da referida instituição, esta iniciativa culminou, em 2011, com a proposta de reestruturação dos Projetos Pedagógicos das cinco habilitações promovendo sua integração em um único projeto pedagógico que estruturava as, agora cinco linhas de formação, em torno de um núcleo comum.

Em 2012, parte da equipe do colegiado do curso de Design compôs uma comissão para a criação do Mestrado Profissional em Design que iniciou suas atividades em 2013.

O histórico acima relatado evidencia o cenário operacional no qual se movimentam os professores que participaram da pesquisa cujos resultados são apresentados ao longo deste artigo. Porém os aspeanctos ideológicos que orientam a equipe estão expressos de forma mais clara na Missão, na Visão e na Proposta Filosófica do curso que de forma sintética podem ser assim resumidos:

\begin{tabular}{|l|l|}
\hline Missão & $\begin{array}{l}\text { "Formar, por meio do ensino, pesquisa e extensão, Designers com } \\
\text { competência par gerar conceitos e gerenciar o processo de design } \\
\text { considerando o desenvolvimento sustentável" }\end{array}$ \\
\hline Visão: & $\begin{array}{l}\text { "Ser uma referencia no sul do país a formação contínua de } \\
\text { designers comprometidos com a comunidade regional e voltados } \\
\text { ao desenvolvimento sustentável". }\end{array}$ \\
\hline $\begin{array}{l}\text { Valores } \\
\text { explicitados na } \\
\begin{array}{l}\text { Proposta } \\
\text { filosófica: }\end{array}\end{array}$ & $\begin{array}{l}\text { Interdisciplinaridade, } \\
\text { Utilização de mídias tecnológicas como recurso didático, } \\
\text { Investimento em práticas de ensino semipresencial, } \\
\text { Indissociabilidade entre ensino, pesquisa e extensão, }\end{array}$ \\
\hline
\end{tabular}




\begin{tabular}{|l|l|}
\hline & $\begin{array}{l}\text { Intensificação do exercício visual e escrito. } \\
\text { Valorização da produção escrita do aluno, considerando as normas } \\
\text { acadêmicas, atendimento a Questões ambientais, } \\
\text { Formação continuada e trabalho em equipe. }\end{array}$ \\
\hline
\end{tabular}

Figura 01: Elementos do cenário Ideológico do curso (PPC, 2011)

O histórico, a missão, a visão e os valores da proposta filosófica acima relatada evidenciam a dinamicidade do curso em se adequar às alterações sócio-geográficas, legais e ao estado-da-arte do conhecimento na área do design. Ressalta-se ainda que aspectos relacionados a educação continuada (que se constitui na abordagem central deste artigo) estão presentes entre os valores da proposta filosófica do curso de Design.

\section{O DESENVOLVIMENTO PROFISSIONAL DOCENTE}

Desenvolvimento profissional, para Marcelo (2009) é o termo que melhor se adéqua à concepção do professor, enquanto profissional do ensino. $O$ autor justifica esta escolha pelo fato da palavra "desenvolvimento" oferecer uma ideia de evolução, continuidade, algo que supera o fosso entre formação docente inicial e continuada. Pode-se compreendê-la, ainda, como atitude permanente de indagação, questionamento e busca de soluções para questões do dia a dia.

De acordo com o autor, trata-se de um processo de longo prazo, individual ou mesmo coletivo, mas centralizado no local de trabalho do docente e que por meio de experiências, tanto formais como informais, contribui para o desenvolvimento de suas competências profissionais.

Marcelo (2009, p. 15) acrescenta que "desenvolvimento profissional e processos de mudança são variáveis intrinsecamente unidas", uma vez que o processo de desenvolvimento profissional deve promover a mudança para que os professores cresçam profissionalmente e pessoalmente. Para tanto, devem ser considerados os preconceitos e crenças dos professores, desde o início de seu percurso profissional, pois influenciarão os modos de aprendizagem e percepção, dos professores, acerca do processo de mudança.

Pode-se questionar se a formação continuada permanente, ou, continuamente oferecida aos professores, pode propiciar o seu desenvolvimento profissional, ou ainda se mudanças significativas ocorrerão caso os docentes não estiverem receptivos ou não tiverem um ambiente favorável.

Neste sentido Imbernón (2009) alerta para uma possível confusão entre terminologias. No âmbito anglo-saxão, principalmente norte-americano, há uma similaridade entre formação permanente e desenvolvimento profissional, o que o torna restrito, pois a única via de desenvolvimento do professorado seria a formação permanente e complementa, explicando que desenvolvimento profissional é um conjunto de fatores que possibilitam ou impedem que o professorado avance em sua vida profissional. Ainda, segundo o autor, a formação é um elemento importante no desenvolvimento profissional; não é o único e, talvez, não seja também decisivo. 
O autor comenta que a profissão docente se desenvolve por diversos fatores: seu salário, a demanda de mercado, o clima do local de trabalho, a promoção, as estruturas hierárquicas, a carreira, etc., e, por suposto, pela formação permanente que o docente vá realizando ao longo de sua vida profissional. A melhoria obtida na formação ajudará no desenvolvimento, mas a melhoria em outros fatores também é decisiva. A formação se legitima então, quando contribui para o desenvolvimento profissional do professorado no âmbito laboral e na melhoria das aprendizagens profissionais. Até por isso, é que o conceito deve incluir ainda um diagnóstico processual e não somente a resolução de necessidades pontuais; deve considerar ainda o professor como membro de um coletivo profissional e incluir políticas, programas e atividades para atendimento das necessidades profissionais. Vale salientar que, segundo Imbernón (2009), um novo conceito deve ser introduzido, o de desenvolvimento profissional coletivo ou institucional, ou seja, de que o desenvolvimento não deve se restringir ao âmbito individual, mas deve abranger todos os envolvidos no processo laboral: a equipe de gestão, os docentes e os demais colaboradores da Instituição de Ensino.

Sabe-se da forte influência dos sistemas de produção e gestão, como modelos que funcionam e que, por isso, podem servir de exemplo para as instituições de Ensino. Nestas estruturas predomina a hierarquização e a divisão do trabalho e as atividades são descritas na forma de processo, ou seja, um conjunto de atividades consecutivas e padronizadas. Da alta administração emanam as diretrizes e cada área as segue, preocupada com o atingimento de seus objetivos. Até por isso é que, muito embora o professor seja a linha de frente e o principal operacionalizador da educação, não há como se desenvolver sem que haja um desenvolvimento coletivo, com o apoio e participação dos gestores institucionais.

Não de forma reducionista, mas pode-se afirmar que o desenvolvimento profissional tem na formação continuada ou permanente algo tangível, palpável, e um de seus componentes mais exequíveis. Por isso, e também pela falta de conhecimento, em muitos casos, a formação continuada é entendida como sinônimo de desenvolvimento profissional. Por outro lado, corre-se o risco, da formação continuada ser vista apenas como preparação do docente para lecionar.

\section{A FORMAÇÃO CONTINUADA E O DESENVOLVIMENTO PROFISSIONAL}

No âmbito das empresas, o desenvolvimento profissional é traduzido por treinamento, nomenclatura importada pelas instituições de ensino, em especial, na esfera do ensino de Administração. Seguindo esta perspectiva, a formação continuada docente assume, o papel de um treinamento. Tachizawa e Andrade (1999, p. 229), afirmam que "o treinamento significa o preparo do professor e funcionário para o cargo, sendo assim uma forma de educação, porquanto a finalidade da educação é preparar o professor e o funcionário para o ambiente dentro ou fora de seu trabalho". Esta denominação transmite uma ideia de uma atividade onde determinados conteúdos serão passados aos professores que deverão reproduzi-los, como uma capacitação para realizar uma determinada atividade, similar a preparar um empregado para operar um equipamento. Este operário será treinado a agir em 
determinadas situações, respondendo de acordo com os padrões estabelecidos. Ao se pensar em treinar, retira-se desse processo a reflexão sobre a prática e, se o objetivo é treinar para determinado fim, não se pode falar de desenvolvimento, de práxis, ou seja, este modelo é limitado e inadequado para o desenvolvimento profissional dos docentes.

Ao caracterizar a atividade docente pela imprevisibilidade, incerteza e por uma relação entre pessoas, as quais têm a sua história de vida, o treinamento demonstra ser algo incompleto e insuficiente para o bom desempenho no universo educativo.

Prada et al. (2001), procuram demonstrar um processo mais abrangente ao defini-lo como capacitação, reciclagem, atualização, aperfeiçoamento ou em termos mais modernos, qualificação e formação continuada. Já Perrenoud (2002, p. 20 e 21), referindo-se à formação continuada, comenta que "aggiornamento, este é o seu nome em italiano; recyclage, assim ele é chamado em algumas regiões de língua francesa". 0 termo reciclagem remete à noção de reaproveitamento, o que parece oportuno considerando-se que os docentes não são como um caderno com páginas em branco, seus saberes são adquiridos através do tempo e provém de sua própria história (TARDIF, 2002), todavia, na língua portuguesa, o termo reciclagem está muito ligado ao reaproveitamento de lixo e resíduos, o que o torna inapropriado.

Gatti e Barreto (2009) explicam que recentemente percebeu-se um movimento de reconceitualização da formação continuada, baseado nas pesquisas relacionadas à identidade profissional do professor, em que a capacitação cede lugar a uma concepção de formação como um contínuo ao longo da vida profissional.

Pode-se dizer que, entre as diferentes nomenclaturas, tem ampla aceitação a ideia da necessidade de uma constante atualização dos docentes. O treinamento, a capacitação ou atividades pontuais não correspondem a esta concepção frente à complexidade do mundo atual. Em que pesem as discussões em relação à nomenclatura mais adequada, um aspecto presente em todas as discussões é a concordância de que é fundamental o modo como à formação é desenvolvida e como seus conteúdos são trabalhados. Também é ponto de consenso entre os pesquisadores que as formações devem ser organizadas a partir dos docentes, que são atores com competência e com saber experiencial. Além disso, deve haver um equilíbrio entre as necessidades dos docentes e os objetivos institucionais.

A preocupação em implementar ações de formação continuada a partir dos docentes e de sua realidade justifica-se na medida em que os participantes têm uma trajetória de vida e de experiências, assim como crenças e conhecimentos sobre o ensino que afetam seu desempenho.

Um aspecto continuamente discutido, em relação à formação continuada. É comum, nas instituições de ensino, uma formação continuada concentrada no início do ano e, em alguns casos, no meio do ano. Esse modelo recebe inúmeras críticas (DEMO, 2000; PRADA et al., 2001), pois são, em geral, palestras ou cursos de poucas horas, sem continuidade e em momentos pontuais. Muitas vezes, são iniciativas que não levam em conta a consulta aos docentes, o levantamento de suas necessidades e a observação dos indicadores gerados por meio da avaliação institucional. Isso faz com que os docentes não se sintam motivados ou mesmo obrigados a participarem, que 
muitas vezes resistam ao que denominam de "pedagogês" e critiquem, por não enxergarem aplicação real no seu cotidiano em sala de aula.

Além das questões, acima apresentadas, outros aspectos que merecem ser considerados na formação continuada dizem respeito ao professor não profissional. Isto porque deve-se considerar que esse professor possui outra atividade e está na instituição, muitas vezes, somente por poucas horas na semana. Daí a importância de considerar mais este fator no planejamento das formações.

De acordo com a pesquisa de Andrade (2006) os professores relatam que aprendem muito mais pelas trocas de experiências com seus pares durante as formações continuadas, pelos erros e acertos destes, do que pelo conteúdo da formação.

Neste sentido, Aguiar (2012, p. 107), afirma que a formação continuada pode contribuir efetivamente para o desenvolvimento profissional se contemplar (1) a reflexão sobre os saberes experienciais; (2) a atualização dos saberes do campo específico [...]; (3) a discussão da função da Universidade e de suas políticas institucionais; (4) a proposta curricular do curso como um todo; (5) o conhecimento da realidade e dos discentes da Instituição.

Percebe-se que ações pontuais, de curta duração, que demonstram ser apenas uma obrigação institucional, que representam uma imposição ou que evidenciem pouco contribuir, com a prática diária dos professores, podem ser inócuas. Ações desligadas da realidade institucional e do contexto de trabalho, sem levantamento, junto aos docentes, de suas necessidades, sem aproveitar as informações da avaliação institucional e que não promovam uma reflexão profunda sobre a prática, também podem ser ineficientes. Da mesma forma, ações de longa duração, continuadas, podem esvaziar-se com o passar do tempo, se não houver comprometimento dos docentes com a Instituição e com a atividade docente, se o contrato de trabalho for por horas trabalhadas e se as estratégias e conteúdos forem inadequados.

Apesar de todas estas vicissitudes, a formação continuada é imprescindível, é um caminho para o desenvolvimento profissional e para um melhor preparo do professor para a atividade docente. Deve ser uma responsabilidade e uma parceria entre Instituição e docentes.

\section{A FORMAÇÃO CONTINUADA EM UMA UNIVERSIDADE COMUNITÁRIA CATARINENSE SOB A ÓTICA DOS DOCENTES DA GRADUAÇÃO EM DESIGN}

Os docentes da Graduação em Design da Universidade Comunitária Catarinense, focalizada no presente artigo, assim como dos demais cursos, têm a obrigatoriedade de participarem no decorrer do ano de formações continuadas que são oferecidas prioritariamente nos períodos de recesso escolar, ou seja, Fevereiro e Julho. Além destes dois momentos, no decorrer do ano, ações específicas ou empreendidas pelos departamentos gestores dos cursos também podem ocorrer, além de atividades semipresenciais. O total de horas de capacitação obrigatória é igual ao número de horas/aula do professor. Se ao final do ano este total de horas de 
capacitação não for cumprido, o número faltante será descontado do salário do docente.

O conteúdo da formação continuada é definido, geralmente, no segundo semestre do ano anterior ao recesso escolar, período prioritário para capacitação. Normalmente um comitê gestor oportuniza que sejam oferecidas atividades conduzidas e patrocinadas pelos departamentos, todavia, a programação principal é planejada e organizada por um setor subordinado à Pró-reitoria de Ensino com base em análise na avaliação docente e nas demandas do Plano de Desenvolvimento Institucional (PDI).

Objetivando conhecer a opinião sobre a formação continuada atualmente oferecida pela Universidade Comunitária Catarinense estudada e sua contribuição para o desenvolvimento profissional dos docentes da Graduação em Design, realizou-se um estudo do tipo survey. O levantamento, ou survey social, como denomina May (2004), baseado em um questionário totalmente estruturado, a ser respondido diretamente pelos sujeitos, é um método bastante difundido na pesquisa social, com a vantagem de possibilitar um significativo incremento no número de participantes.

De um total de 32 possíveis participantes, na época em que a pesquisa foi realizada (segundo semestre de 2012), 17 professores responderam a um questionário composto por um total de 19 perguntas.

Deve-se ressaltar que, neste artigo, optou-se por apresentar uma síntese dos aspectos mais relevantes e relacionados com o escopo do tema proposto, ou seja, nem todos os dados tabulados serão retratados.

Por meio de perguntas relacionadas à formação e titulação do docente, tempo de casa, carga-horária semanal e atividades profissionais, procurou-se conhecer o perfil dos docentes da Graduação em Design. 58\% dos docentes atuam a até 5 anos na Instituição, $42 \%$ a até 10 anos ou mais. $70 \%$ dos respondentes são Mestres e 11\% estão cursando o mestrado. $23 \%$ dos respondentes são Doutores e $12 \%$ estão com seu doutoramento em andamento. 65\% dos respondentes atuam até 20 horas semanais na Instituição e 35\%, mais de 20 horas semanais. 59\% dos respondentes declararam que sua única ocupação profissional é a docência. $88 \%$ dos docentes não são licenciados, professores não profissionais, ou seja, sem formação pedagógica.

De forma objetiva questionou-se, como o respondente considerava a contribuição da profissionalização docente atualmente oferecida pela Instituição, para a sua atividade docente. Os resultados podem ser melhor avaliados por meio do gráfico 1. 


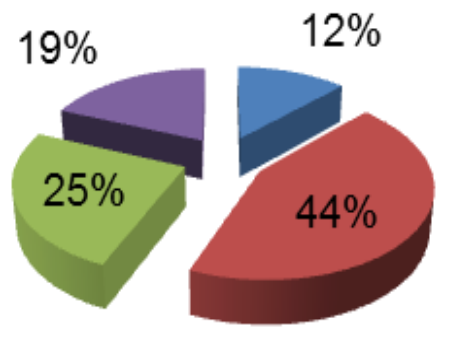

- Não é importante

-É pouco importante

-É importante

-É muito importante

Gráfico 1 - Respostas ao questionamento: como você considera a contribuição da profissionalização docente atualmente oferecida pela Instituição para a sua atividade docente?

Fonte: Primária (2013)

A maior parte dos respondentes considerou como pouco importante a formação continuada, atualmente oferecida pela Instituição, para a sua atividade docente. Muito embora 95\% dos professores tenha declarado que é necessário ou muito necessário atualizar-se didaticamente, apenas $65 \%$ declararam que sua principal opção para atualização é a leitura por conta própria de assuntos na área e a troca de experiências com outros docentes. A profissionalização atualmente oferecida é o principal mecanismo apenas para $12 \%$ dos respondentes. Quanto a atualizar-se no campo das disciplinas que atualmente lecionam na Instituição, 82\% declararam que é necessário ou muito necessário atualizar-se e, para tanto, nenhum dos respondentes considera a Profissionalização docente atualmente oferecida pela Instituição como a principal opção para atender à esta demanda.

Percebe-se uma coerência entre a avaliação da Profissionalização docente e as ações de atualização empreendidas pelos docentes e neste sentido, a fala de dois professores, pode ser utilizada para compreender melhor a realidade institucional acerca da Profissionalização docente.

"acredito que a contribuição da profissionalização docente é válida e deve continuar sendo oferecido. A questão é que ao passar dos anos os assuntos e as oficinas acabam se desgastando sobre os mesmos pontos debatidos e realizados". (Professor "A", 2012)

"sugiro que a profissionalização docente seja mais específica, gerenciada pelos departamentos, visando discutir / resolver problemas detectados no ensinoaprendizagem de cada curso, bem como prover a atualização dos professores". (Professor "B", 2012)

Os docentes foram profícuos quanto às sugestões, e apresentaram inúmeras. Para tanto, foram questionados a contribuírem com temas relacionados às 
competências listadas no Plano de Desenvolvimento Institucional (PDI), o qual se divide em quatro eixos.

Quanto a competência técnico-científica, o primeiro eixo, que para a Instituição diz respeito a ser capaz de se manter atualizado em relação a sua área de conhecimento, ser capaz de abordar os conteúdos referentes a sua área de conhecimento, considerando as exigências de formação previstas no planejamento pedagógico do curso, bem como a indissociabilidade entre ensino, pesquisa e extensão, os docentes sugeriram ações na forma de oficinas, onde docentes dividiriam seus conhecimentos com os demais e capacitações mais específicas como tipografia, computação gráfica, design de interface, Crame Design, entre outras.

Em relação ao segundo eixo, a competência pedagógica, considerada como a capacidade de organizar e dirigir situações de aprendizagem em que atue como orientador e mediador; ser capaz de empregar metodologias de aprendizagem inovadoras; ser capaz de empregar novas tecnologias de informação e comunicação em situações de aprendizagem; ser capaz de acompanhar e avaliar a efetividade das situações de aprendizagem em relação ao perfil do egresso e aos objetivos de aprendizagem, a palavra de ordem dos docentes foi inovação. Sugeriram ações relacionadas a metodologias de ensino, acompanhamento e avaliação inovadoras, novas tecnologias e estratégias de ensino e temas mais específicos, como ferramentas e tendências de mercado e arte.

A competência relacional, o terceiro eixo, que no PDI significa ser capaz de agir e de orientar os estudantes quanto ao respeito à vida, à dignidade, à liberdade, à democracia, à diversidade, ao meio ambiente, às relações humanas, levando em conta valores e atitudes éticos por meio do diálogo e do respeito ao outro, também foi contemplada, com sugestões como: a relação professor aluno e relações humanas no ambiente pedagógico. Sugere-se ainda, a troca de experiência entre os docentes da área.

O quarto eixo temático, a competência organizacional, ou seja, a capacidade de agir em conformidade com o estatuto, os regimentos e as resoluções da Instituição; atuar de forma comprometida com as concepções, a visão, a missão, os valores, princípios e as diretrizes da Universidade, foi o menos contemplado por sugestões, em comparação aos demais. Apenas aventou-se a necessidade de melhor divulgação do regimento interno da Instituição.

\section{CONCLUSÃO}

Com base nos dados analisados pode-se dizer que os professores da Graduação em Design da Universidade Comunitária Catarinense em questão, sentem que precisam atualizar-se e, muito embora a formação continuada a que têm acesso não seja a ideal, não ficam acomodados e procuram atualizar-se por iniciativa própria. São docentes experientes e com uma titulação adequada à sua atividade, do ponto de vista técnico-científico, pois em sua maioria, são docentes não profissionais (não licenciados), mas que encontraram na docência sua profissão, visto que esta é a única atividade profissional da maior parte dos que participaram da pesquisa. 
Sua insatisfação com a Formação Continuada, atualmente oferecida pela Instituição, ficou evidente quando demonstraram a pouca importância que a mesma tem em relação ao seu desenvolvimento profissional e, percebe-se que a principal causa desta avaliação é que a mesma não contempla questões pontuais e especificidades da Graduação em Design.

As sugestões apresentadas aos dois primeiros eixos temáticos (competências técnico-científicas e pedagógicas) demonstram demandas por inovação e atualização tecnológica específicas da área, aspectos que seriam dificilmente contemplados em ações de capacitação Institucionais, onde todos os docentes das mais diversas áreas participam.

Em relação aos dois últimos eixos temáticos (competência relacional e organizacional), percebe-se que os conteúdos sugeridos apontam para questões mais universais, todavia, relacionado estes dados à sugestão de oficinas para troca de experiências, pode-se considerar que nos eventos onde participam docentes de outros tantos cursos, talvez os professores de Design não percebam situações de seu cotidiano ou não tenham suas especificidades novamente contempladas.

Muito embora a Instituição paute seu planejamento com base na Avaliação Docente e no PDI e, desta forma, tenha que definir ações mais abrangentes, sugere-se que a mesma oportunize uma maior participação dos docentes por áreas de conhecimento e, desta forma, contemple demandas específicas.

\section{Referências}

AGUIAR, Victor. Formação continuada e desenvolvimento profissional dos docentes de administração. Tese (Doutorado em Educação: Psicologia da Educação) São Paulo: São Paulo, 2012.

ANDRADE, Telga P. P. de. O professor universitário sem formação pedagógica, a origem e a construção de sua práxis docente: que racionalidade? Que caminhos? Tese (Doutorado em Educação Brasileira) Ceará: Fortaleza, 2006.

DEMO, Pedro. Conhecer \& aprender: sabedoria dos limites e desafios. Porto Alegre: Artes Médicas Sul, 2000.

GATTI, Bernardete A.; BARRETO, Elba S. de Sá. Professores do Brasil: impasses e desafios. Brasília: UNESCO, 2009.

IMBERNÓN F. Una nueva formación permanente del profesorado para un nuevo desarrollo profesional y colectivo. Revista Brasileira de Formação de Professores, América do Norte, 12032009. 
Formação docente e profissional: formar-se para a mudança e a incerteza. 7 ed. São Paulo: Cortez, 2009.

MARCELO, Carlos. Desenvolvimento Profissional Docente: passado e futuro. Sisifo. Revista de Ciências da Educação, 08, jan/abril 2009, p. 7-22. Disponível em: <http://sisifo.fpce.ul.pt>. Acesso em: 13 mar. 2010.

MAY, Tim. Pesquisa social: questões, métodos e processos. Porto Alegre: Artmed, 2004.

PERRENOUD, Philippe. A prática reflexiva no ofício de professor: profissionalização e razão pedagógica. Porta Alegre: Artmed Editora, 2002.

PRADA. Luis E. A. et al. Educação Continuada: o discurso oficial, a política e a utopia. Textos geradores e resumos. VI Congresso Estadual Paulista sobre formação de Educadores. São Paulo: Águas de Lindóia, 2001.

TACHIZAWA, Takeshy; ANDRADE, Rui B. O. Gestão de Instituições de Ensino. Rio de Janeiro: Editora Fundação Getúlio Vargas, 1999.

TARDIF, Maurice. Saberes docentes e formação profissional. Petrópolis: Vozes, 2002. 